\title{
TINJAUAN AWAL \\ ALOKASI PEMANFAATAN SUMBER DAYA BATUBARA KALORI RENDAH DI SUMATERA
}

\section{PREVIEW ON RESOURCE ALLOCATION FOR LOW CALORIE COALS IN SUMATERA}

\author{
Oleh: \\ Asep Suryana dan Fatimah \\ Pusat Sumber Daya Geologi \\ JI. Soekarno Hatta No. 444 Bandung
}

\section{SARI}

Batubara kalori rendah tersebar cukup banyak di Sumatera. Potensi ini belum termanfaatkan secara optimal karena terkendala oleh berbagai faktor, antara lain nilai jual yang tidak ekonomis. Alokasi pemanfaatan batubara kalori rendah perlu dilakukan dalam upaya memanfaatkan potensi alam ini secara optimal. Tinjauan alokasi potensi batubara ini dilakukan dengan mengelompokkan potensi batubara yang lokasinya berdekatan dan dapat dimanfaatkan untuk tujuan yang sama. Hasil tinjauan ini menunjukkan bahwa batubara kalori rendah Sumatera dapat dialokasikan untuk proses gasifikasi batubara, pencairan batubara serta penaikan peringkat batubara.

Kata kunci: alokasi, batubara kalori rendah, Sumatera, gasifikasi, pencairan batubara, penaikan peringkat

\section{ABSTRACT}

Low calorie coals are distributed widely in Sumatra. Optimum utilization has not obtained yet due to several obstacles such as uneconomic selling value. Review on coal allocation has been carried out by grouping coal potential in the nearby location which can be utilized for the same purpose. It can be concluded that low calorie coal of Sumatra can be allocated for coal gasification, coal to liquid, as well as upgrading coal rank.

Keywords: allocation, low calorie coal, Sumatra, gasification, coal liquifaction, upgrading

\section{PENDAHULUAN}

Sumatera merupakan salah satu pulau di Indonesia, yang memiliki potensi batubara terbanyak. Sumber daya batubara Sumatera saat ini mencapai 64.592,37 juta ton, dengan cadangan batubara sebesar $14.799,99$ juta ton yang kualitasnya bervariasi, mulai dari batubara kalori tinggi sampai batubara kalori rendah (Anonim, 2011).

Berdasarkan kajian Tim Pusat Sumber Daya Geologi Tahun 2011, sekitar $30 \%$ dari sumber daya batubara yang terdapat di Sumatera merupakan batubara kalori rendah dengan nilai kalori batubara di bawah $5.100 \mathrm{kal} / \mathrm{gr}(\mathrm{adb})$. Batubara kalori rendah ini tersebar hampir di seluruh daerah di Sumatera mulai dari Provinsi Nangroe Aceh Darusalam, Sumatera Utara, Riau (daratan), Jambi, Bengkulu, Sumatera
Selatan dan Provinsi Lampung. Pada beberapa tempat endapan batubara kalori rendah ini telah ditambang, baik dalam skala besar maupun skala kecil (tambang rakyat). Sebagian hasil penambangan dialokasikan untuk ekspor dengan harga yang rendah sekali. Namun, masih banyak batubara kalori rendah di Sumatera yang belum ditambang dikarenakan oleh berbagai alasan, misalnya akibat adanya tumpang tindih lahan ataupun karena lokasinya yang cukup jauh dari sarana infrastruktur yang ada, sehingga batubara tersebut dianggap kurang ekonomis untuk ditambang, mengingat biaya transportasi yang cukup mahal. Batubara yang masih belum ditambang tersebut perlu dikelola dengan baik agar manfaat potensi sumber daya alam ini bisa dioptimalkan dan tidak hanya dirasakan oleh para pelaku 
pengusaha batubara, melainkan dapat dirasakan juga oleh masyarakat di sekitarnya.

Maksud tinjauan ini adalah untuk mengetahui lokasi terdapatnya batubara kalori rendah di Sumatera agar dapat ditentukan alokasi pemanfaatannya. Tujuannya adalah sebagai bahan pertimbangan untuk perencanaan pemanfatan batubara Sumatera. Diharapkan tinjauan ini dapat dipakai sebagai salah satu acuan bagi para pemangku keputusan dalam perencanaan pemanfaatan batubara kalori rendah di Sumatera, agar sumber daya alam yang tak dapat diperbaharui ini dapat dimanfaatkan secara optimal.

\section{METODOLOGI}

Pengelompokkan sumber daya batubara kalori rendah di Sumatera ini masih berupa tinjauan awal yang bersifat global. Data yang digunakan berupa data sekunder potensi batubara Sumatera yang bersumber dari Pemutakhiran Data dan Neraca Energi Fosil yang disusun oleh Pusat Sumber Daya Geologi, Badan Geologi (Anonim, 2011). Data tersebut dikelompokkan berdasarkan nilai potensinya (sumber daya dan cadangan batubara), lokasi keberadaan potensi batubara tersebut dan dikaitkan dengan kemudahan pencapaian ke lokasi tersebut serta keberadaan infrastruktur penunjang lainnya (misalnya jalur pipa gas). Asumsinya, batubara yang berada jauh dari pantai dapat dimanfaatkan dengan proses gasifikasi (coal gasification) ataupun pencairan batubara (coal to liquid) dengan pabrik gasifikasi/pencairan di dekat tambang batubara. Hal ini didasari oleh pemikiran bahwa pengangkutan batubara tidaklah murah oleh karena itu lebih baik mengangkut produk akhir yang berupa gas atau minyak. Sedangkan untuk batubara yang berlokasi di dekat pantai/pelabuhan dapat diproses dengan Upgrading Brown Cool (UBC) dan pabrik UBC bisa berlokasi dimana saja.

Beberapa potensi batubara yang lokasinya berdekatan kemudian digabungkan dalam 1 (satu) kelompok untuk memudahkan pemanfaatan potensi batubara tersebut. Kelompok ini dinamai berdasarkan potensi terbesar pada kelompok tersebut, misalnya potensi batubara kalori rendah di provinsi Riau adalah daerah Cerenti, maka kelompok tersebut dinamakan Kelompok Cerenti. Pembangunan pabrik pemanfaatan batubara juga disarankan pada lokasi dengan potensi batubara terbesar.

\section{TEKNOLOGI PEMANFAATAN BATUBARA}

Batubara diyakini memberikan dampak buruk bagi lingkungan yang diakibatkan oleh produk sampingan hasil pembakaran langsung. Oleh karena itu berbagai penelitian telah dilakukan untuk mereduksi dampak tersebut dengan mengembangkan berbagai teknologi pemanfaatan batubara yang diyakini lebih ramah lingkungan. Beberapa teknologi tersebut diantaranya akan diuraikan berikut ini.

\section{Gasifikasi batubara}

Gasifikasi batubara merupakan suatu proses yang dilakukan untuk menghasilkan gas sintetik (syngas). Komposisi gas sintetik yang dihasilkan terdiri dari karbon monoksida (CO), hidrogen $\left(\mathrm{H}_{2}\right)$, karbondioksida $\left(\mathrm{CO}_{2}\right)$ dan uap air $\left(\mathrm{H}_{2} \mathrm{O}\right)$. Konversi batubara menjadi gas ini dilakukan dalam sebuah reaktor, baik dengan menggunakan pereaksi ataupun tanpa menggunakan pereaksi. Pereaksi tersebut dapat berupa udara, campuran udara/uap air ataupun campuran oksigen/uap air (Suprapto, 2011).

\section{Pencairan batubara}

Pencairan batubara merupakan proses yang dilakukan untuk menghasilkan bahan bakar cair sintetik dari batubara. Penelitian dan pengembangan konversi batubara menjadi bahan bakar cair ini dilandasi pemikiran untuk pencarian sumber bahan bakar cair lain selain minyak bumi yang cadangannya semakin berkurang. Proses pencairan batubara diawali dengan proses gasifikasi batubara untuk menghasilkan gas sintetik. Selanjutnya gas sintetik ini diproses kembali dengan menggunakan suatu katalis untuk menghasilkan bahan bakar cair. Beberapa negara sudah mulai melakukan demo plant untuk pencairan batubara ini diantaranya Cina. Pencairan batubara yang dilakukan di 
Cina menghasilkan bahan bakar cair dengan komposisi $70 \%$ minyak diesel, $20 \%$ nafta, 10\% LPG (Liquefied petroleum gas) dan produk minor lainnya (Suprapto, 2011).

\section{Penaikan peringkat batubara}

Penaikan peringkat batubara (Upgrading Brown Coal/UBC) merupakan proses peningkatan kualitas batubara peringkat rendah untuk menghasilkan batubara dengan kualitas menyerupai batubara peringkat tinggi (bituminous). Nilai kalori batubara peringkat rendah seperti lignit dan sub-bituminous berkisar 3.500 $5.000 \mathrm{kkal} / \mathrm{kg}$ dapat ditingkatkan menjadi batubara peringkat tinggi dengan kalori 6.200 - $7.000 \mathrm{kkal} / \mathrm{kg}$ melalui penurunan kadar air (Umar, 2011).

\section{HASIL TINJAUAN}

Kriteria yang digunakan dalam evaluasi ini yaitu potensi, jarak antar lokasi, dan akses. Evaluasi data menghasilkan 7 kelompok batubara kalori rendah yang tersebar di wilayah Sumatera (Tabel 1 dan Gambar 1). Setiap kelompok memiliki total sumber daya batubara lebih dari 100 juta ton. Hal ini dilandasi pertimbangan bahwa saat ini di Indonesia telah dikembangkan reaktor gasifikasi batubara dengan kapasitas $150 \mathrm{~kg}$ batubara/jam (http://www.tekmira.esdm.go.id, 2012). Asumsinya, batubara yang dibutuhkan reaktor tersebut sekitar 10 juta ton/tahun, sehingga dengan potensi minimal 100 juta ton batubara maka pabrik pengolahan batubara tersebut diperkirakan akan bertahan paling tidak selama 10 tahun.

Kelompok pertama adalah Kelompok Batubara Kalori Rendah Meulaboh yang terdapat di Nanggroe Aceh Darussalam (NAD). Potensi batubara ini terletak tidak jauh dari pantai. Akses untuk membawa batubaranya keluar dari daerah Meulaboh relatif mudah. Berdasarkan kriteria tersebut, batubara kalori rendah daerah ini dapat dialokasikan untuk upgrading. Namun sumber daya batubara yang jumlahnya sekitar 97,76 juta ton masih harus dipertimbangkan lagi, karena jika sumber daya batubaranya kurang memadai maka ada kemungkinan secara ekonomi tidak akan menguntungkan. Oleh karena itu harus dicari lagi batubara kalori rendah dari lokasi lain yang memungkinkan untuk ditambahkan, sehingga mempunyai nilai ekonomis. Batubara daerah Nias (Sumatera Utara) yang jumlahnya sekitar 19,97 juta ton bisa dimanfaatkan untuk menunjang alokasi upgrading di Meulaboh, mengingat lokasi Nias paling dekat ke Meulaboh dan transportasinya bisa menggunakan

Tabel 1. Zonasi Batubara yang dialokasikan untuk CTL, UBC dan Gasifikasi

\begin{tabular}{|c|c|c|c|c|c|c|c|}
\hline \multirow{3}{*}{ No. } & \multirow{3}{*}{ Kelompok } & \multirow{3}{*}{ Lokasi Batubara } & Sumberdaya & Cadangan & Total & Total & \multirow{3}{*}{ Alokasi } \\
\hline & & & 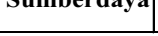 & Canaingan & Sumberdaya & Cadangan & \\
\hline & & & \multicolumn{4}{|c|}{ (Juta Ton) } & \\
\hline \multirow{2}{*}{1} & \multirow{2}{*}{ Meulaboh } & Aceh Barat (NAD) & 91,76 & & \multirow{2}{*}{111,73} & & \multirow{2}{*}{ Upgrading } \\
\hline & & Nias (Sumatera Utara) & 19,97 & & & & \\
\hline \multirow{6}{*}{2} & \multirow{6}{*}{ Cerenti } & Cerenti (Riau) & $1.340,63$ & 569,07 & \multirow{6}{*}{$1.464,36$} & \multirow{6}{*}{569,07} & \multirow{6}{*}{ Gasifikasi/CTL } \\
\hline & & Peranap (Indragiri Hulu-Riau) & 7,76 & & & & \\
\hline & & Pelalawan (Riau) & 23,5 & & & & \\
\hline & & Lubuk Jambi (Riau) & 21,00 & & & & \\
\hline & & Kuantan Mudik (Riau) & 22,59 & & & & \\
\hline & & Tanjung Jabung (Jambi) & 48,88 & & & & \\
\hline \multirow{7}{*}{3} & \multirow{7}{*}{ Bayat } & Sungai Gedang (Merangin-Jambi) & 2,25 & & \multirow{7}{*}{$5.798,15$} & \multirow{7}{*}{$2.821,98$} & \multirow{7}{*}{ Upgrading } \\
\hline & & Air Tenang (Bengkulu) & 21,92 & & & & \\
\hline & & Bayat $(\mathrm{MuBa}-$ SumSel $)$ & $3.169,23$ & $2.597,26$ & & & \\
\hline & & Bentayan (MuBa - SumSel) & 92,22 & & & & \\
\hline & & Lbk. Mahang (MuBa - SumSel) & $1.892,78$ & 123,19 & & & \\
\hline & & Bayung Lincir (MuBa - SumSel) & 323,5 & & & & \\
\hline & & Babattoman (MuBa - SumSel) & 296,25 & 101,53 & & & \\
\hline \multirow{2}{*}{4} & \multirow{2}{*}{$\begin{array}{l}\text { Sigoyang } \\
\text { Benuang }\end{array}$} & Sigoyang Benuang (M.Enim - SumSel) & $9.286,52$ & $2.246,83$ & \multirow{2}{*}{$10.121,44$} & \multirow{2}{*}{$2.246,83$} & \multirow{2}{*}{ Gasifikasi/CTL } \\
\hline & & Lembak (M.Enim - SumSel) & 834,92 & & & & \\
\hline \multirow{3}{*}{5} & \multirow{3}{*}{ Pengadonan } & Pengadonan (OKU - SumSel) & 275,79 & & \multirow{3}{*}{569,86} & \multirow{3}{*}{28,47} & \multirow{3}{*}{ Gasifikasi/CTL } \\
\hline & & Tj. Lubuk (OKU - SumSel) & 272,4 & 28,47 & & & \\
\hline & & Kartanegara (OKU - SumSel) & 21,67 & & & & \\
\hline \multirow[b]{2}{*}{6} & \multirow{2}{*}{ Tanah Abang } & T1. Karangan (OKUTim - SumSel) & 23,74 & & \multirow{2}{*}{356,80} & & Gasifikasi/CTL \\
\hline & & Tanah Abang (OKUTim - SumSel) & 333,06 & & & & Gasıfikasi/C IL \\
\hline 7 & Pagar Dewa & Pagar Dewa (OKI - SumSel) & 329,18 & & 329,18 & & Upgrading \\
\hline
\end{tabular}




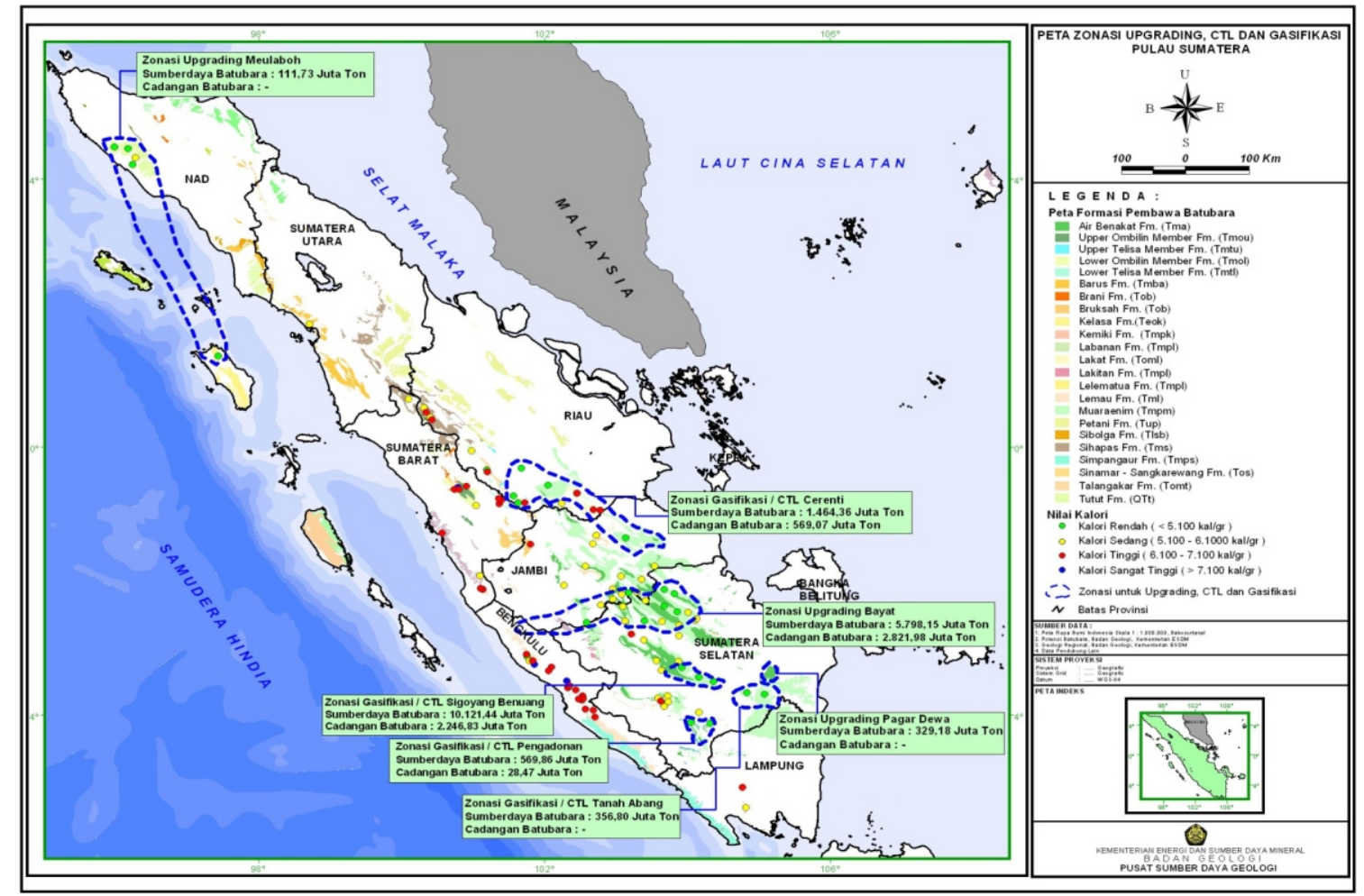

Gambar 1. Zonasi Batubara yang dialokasikan untuk CTL, UBC dan Gasifikasi

transportasi laut. Diharapkan, dengan sumber daya batubara sekitar 100 juta ton proses upgrading batubara bisa mempunyai nilai ekonomis.

Kelompok Batubara Kalori Rendah Cerenti sebagian besar terdiri dari batubara di Provinsi Riau (daratan) yaitu dari daerah Cerenti, Peranap, Pelalawan, Lubuk Jambi dan Kuantan Mudik. Sumber daya batubara daerah Cerenti, Peranap, dan Pelalawan sekitar $1.489,92$ juta ton (1,5 milyar ton) ditambah cadangan sekitar 620,48 juta ton, dapat dialokasikan untuk gasifikasi ataupun dicairkan. Demikian juga untuk batubara kalori rendah daerah Lubuk Jambi dan Kuantan Mudik yang mempunyai sumber daya sekitar 43,59 juta ton dialokasikan untuk gasifikasi atau CTL, dengan tempat pengolahannya digabungkan dengan kelompok batubara Cerenti, Peranap dan Pelalawan. Tempat pengolahan di daerah Cerenti ini dipilih karena selain mempunyai sumber daya lebih dari 1 milyar ton, di wilayah ini juga sudah ada sarana penunjang berupa jaringan pipa minyak dan gas.

Provinsi Jambi, yang terletak berbatasan di sebelah selatan dengan
Provinsi Riau, memiliki potensi batubara kalori rendah di dua lokasi yaitu Tanjung Jabung dan Sungai Gedang (Kabupaten Merangin). Sumber daya batubara daerah Tanjung Jabung sekitar 48,88 juta ton, sedangkan daerah Sungai Gedang hanya sekitar 2,25 juta ton. Besarnya sumber daya batubara dari dua lokasi hanya sekitar 50 juta ton, sehingga tidak memungkinkan untuk membangun tempat pengolahan batubara di Jambi. Untuk memperoleh nilai ekonomis maka batubara kalori rendah dari Tanjung Jabung dapat diproses di tempat pengolahan terdekat, yaitu di Cerenti, Provinsi Riau. Namun, batubara dari Sungai Gedang tidak memungkinkan untuk diproses di Cerenti, karena jarak yang terlalu jauh (melalui jalan darat). Lokasi terdekat dari Sungai Gedang yang mempunyai sumber daya batubara dalam jumlah besar adalah Provinsi Sumatera Selatan, sehingga pengolahan batubara Sungai Gedang bisa diangkut ke Provinsi Sumatera Selatan, yaitu ke wilayah Musi Banyuasin.

Provinsi Sumatera Selatan merupakan provinsi dengan potensi batubara terbesar di Sumatera dengan lokasi batubara yang tersebar di beberapa 
kabupaten. Batubara kalori rendah di Provinsi Sumatera Selatan terdapat di Kabupaten Musi Banyuasin (MuBa), Kabupaten Muara Enim, Kabupaten Ogan Komering Ulu (OKU), Kabupaten Ogan Komering Ulu Timur (OKUTim) dan Kabupaten Ogan Komering Ilir (OKI). Oleh karena itu batubara kalori rendah di Provinsi Sumatera Selatan dikelompokkan menjadi Kelompok Bayat, Kelompok Sigoyang Benuang, Kelompok Pengadonan Kelompok Tanah Abang dan Pagar Dewa.

Kelompok Bayat terdiri dari batubara kalori rendah di Kabupaten Musi Banyuasin dengan sumber daya batubara sebesar $5.773,98$ juta ton (5,7 milyar ton) dan cadangan sebesar 2.821,98 (2,8 milyar ton). Potensi batubara ini terdapat di daerah Bayat, Bentayan, Lubuk Mahang, Bayung Lincir, dan Babat Toman. Batubara di Kabupaten Musi Banyuasin ini dialokasikan untuk gasifikasi ataupun dicairkan. Seperti yang telah diulas sebelumnya, Kelompok Bayat ini juga mendapat tambahan batubara dari daerah Sungai Gedang, Kabupaten Merangin, Provinsi Jambi sebesar 2,25 juta ton. Selain itu, batubara kalori rendah Provinsi Bengkulu, yaitu dari daerah Air Tenang, Kabupaten Bengkulu Utara, juga dapat diangkut ke Bayat, Kabupaten Musi Banyuasin, untuk diolah dengan proses gasifikasi ataupun pencairan. Sumber daya batubara kalori rendah daerah Air Tenang adalah sebesar 21,92 juta ton.

Kelompok Sigoyang Benuang hanya berasal dari dua lokasi batubara di Kabupaten Muara Enim, yaitu Sigoyang Benuang dan Lembak. Walaupun hanya berasal dari dua lokasi, namun potensi batubara kalori rendah daerah Sigoyang Benuang sangat besar dibandingkan daerah lainnya di Sumatera yaitu sumber daya batubara sebesar 9.286,52 juta ton dan cadangan $2.246,83$ juta ton, apabila dijumlahkan dengan potensi batubara daerah Lembak, maka Kelompok Sigoyang Benuang ini memiliki sumber daya batubara kalori rendah sebesar $10.121,44$ juta ton dengan cadangan sebesar $2.246,83$ juta ton. Potensi batubara yang besar ini dialokasikan untuk gasifikasi ataupun dicairkan.

Kelompok Pengadonan yang terletak di Kabupaten Ogan Komering Ulu $(\mathrm{OKU})$ memiliki sumber daya batubara kalori rendah sebesar 569,86 juta ton dan cadangan sebesar 28,47 juta ton. Batubara ini terdapat di daerah Pengadonan, Tanjung Lubuk, dan Kartanegara. Pemanfaatan batubara kalori rendah di Kabupaten OKU ini dialokasikan untuk gasifikasi ataupun dicairkan. Sama halnya dengan batubara kalori rendah di Kabupaten OKU, batubara kalori rendah di Kabupaten OKU Timur juga dialokasikan untuk gasifikasi ataupun dicairkan. Jumlah sumber daya batubara kalori rendah Kabupaten OKU Timur sekitar 356,80 juta ton yang berasal dari daerah Talang Karangan dan Tanah Abang, Kabupaten OKU Timur.

Batubara kalori rendah dari Kabupaten Ogan Komering Ilir hanya terdapat di daerah Pagar Dewa dengan sumber daya sebesar 329,18 juta ton. Mengingat lokasinya yang dekat ke pantai, maka batubara di daerah ini dapat dialokasikan untuk upgrading.

\section{PENUTUP}

Tulisan ini hanya berupa tinjauan yang bersifat umum dengan asumsi-asumsi sederhana dan dititik beratkan pada potensi batubara kalori rendah di Sumatera. Tinjauan ini belum mempertimbangkan aspek-aspek lain seperti misalnya keberadaan air untuk penunjang pabrik pengolahan, kemungkinan besarnya gas karbon dioksida $\left(\mathrm{CO}_{2}\right)$ yang akan dihasilkan pada proses ini, ataupun kajian keekonomisan terkait antara besarnya potensi batubara dengan biaya produksi saat pengolahan. Untuk itu diperlukan kajian lebih lanjut apabila hasil tinjauan ini akan diimplementasikan.

\section{UCAPAN TERIMAKASIH}

Penulis menghaturkan terima kasih kepada Ir. Deddy Amarullah dan Sigit Arso Wibisono, ST. yang telah membantu dalam penyusunan makalah ini. 


\section{MAKALAH ILMIAH}

\section{DAFTAR PUSTAKA}

Anonim, 2011, Laporan Pemutakhiran Data dan Neraca Energi Fosil Tahun 2011, Pusat Sumber Daya Geologi. Bandung.

Suprapto, S.J., 2011, Mengejar Nilai Tambah Batubara, Geomagz Vol. 1 No.3-2011, Badan Geologi, Bandung.

Suprapto, S., 2011, Perkembangan Teknologi Gasifikasi Batubara, bahan presentasi pada Kolokium Pertambangan 2011, Pusat Penelitian dan Pengembangan Teknologi Mineral dan Batubara, Bandung.

Umar, D.F., 2011, Perkembangan Teknologi Upgrading, bahan presentasi pada Kolokium Pertambangan 2011, Pusat Penelitian dan Pengembangan Teknologi Mineral dan Batubara, Bandung.

http://www.tekmira.esdm.go.id/HasilLitbang/?p=377 Pembuatan Reaktor Gasifikasi Batubara Kapasitas $150 \mathrm{~kg}$ batubara / jam. Diunduh tanggal 6 November 2012. 